\section{Hinweise auf Mimivirus nicht bestätigt}

Bei dem kürzlich entdeckten Mimivirus lag die Vermutung nah, dass es eine pathogene Rolle bei Atemwegserkrankungen spielt. Bei Pneumonie-Patienten waren in Studien Antikörper gegen das Virus aufgetreten. Untersuchungen eines niederländischen Teams konnten dessen Präsenz in einer Studienpopulation mit Patienten, die unter chronisch obstruktiver Lungenerkrankung (COPD) litten, jedoch nicht bestätigen. Respir Med 2012; 106: 1690-1694

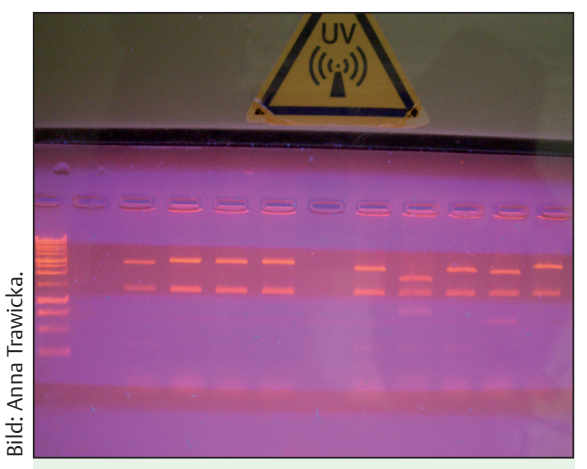

Über die Polymerasekettenreaktion (PCR) und die anschließende Gelelektrophorese (hier ein Beispiel) kann die DNA von Viren auch in kleinen Mengen nachgewiesen werden.

Der Acanthamoeba-polyphaga-Mimivirus ist ein gigantischer DNA-Virus. Frühere Studien mit schwer kranken, meist ventilierten Patienten erbrachten Hinweise darauf, dass er, ähnlich wie andere amöbenassoziierte Mikroorganismen, eine Rolle bei der respiratorischen Pathologie spielen und zur Exazerbation von COPD beitragen könnte. M. J. Vanspauwen von der Universität Maastricht und Kollegen überprüften diese Annahme. Dazu sammelten sie Sputumproben während der stabilen Phase und im Verlauf von Exazerbationen von COPD-Patienten, die an einer pulmonalen Rehabilitation teilnahmen. Die Mikrobiologen untersuchten alle Sputumproben mittels Echtzeit-PCR auf Mimiviren. Außerdem analysierten sie Serumproben hinsichtlich der Präsenz von Antikörpern gegen dieses Virus.

Die in die Untersuchung aufgenommenen 109 Patienten wiesen ein mittleres Alter von 66 Jahren bei einer Altersspanne von 42-85 Jahren auf. 31 Patienten waren
Raucher, 78 hatten das Rauchen aufgegeben. Insgesamt waren 220 Sputumproben für die Auswertung geeignet. 115 Proben stammten aus der stabilen Phase des Rehabilitationsprogramms, 105 aus der Exazerbationsphase. Von den 118 Serumproben für die Antikörperanalyse stammten 30 aus der Exazerbationsphase und 88 aus der stabilen Phase.

\section{Keine Mimivirus-DNA im Sputum $\nabla$}

Die Forscher konnten in keiner der Sputumproben Mimivirus-DNA mittels Echtzeit-PCR entdecken. Zusätzliche Tests mittels Gelelektrophorese brachten ebenfalls keine positiven Ergebnisse. In $3 \mathrm{Se}-$ rumproben (2 davon während der Exazerbation gesammelt) von 3 Patienten fanden die Forscher Antikörper gegen den Mimivirus. Nur in einer Probe stieg der Antikörpertiter an.

\section{Fazit}

Nach Angaben der Autoren ist dies die erste Studie, die sich mit dem Mimivirus bei COPD-Patienten in der pulmonalen Rehabilitation befasst. In dieser Population fanden sich keine eindeutigen Hinweise auf Mimiviren im Sputum oder auf Antikörper im Serum. Als mögliche Erklärungen führen die Autoren eine virale Belastung unterhalb des Entdeckungslimits oder das Auftreten eines Polymorphismus im Amplifikationsbereich auf, der zu negativen PCR-Ergebnissen geführt haben kann. Bisher bleibt somit die Rolle des Mimivirus bei der akuten Exazerbation von COPD unklar.

Dr. Volker Kriegeskorte, Buchloe
Rauchen

\section{Studie fordert staatliche Regulierung}

Die britische Regierung könnte Einnahmen von 500 Mio. Pfund (rund 603 Mio. Euro) pro Jahr erhalten, indem sie den Profit der Zigarettenhersteller einschränkt. Zu diesem Ergebnis kommt eine Studie an der University of Bath. Das Team um Robert Branston fordert für Rauchwaren eine ähnliche staatliche Regulierung wie beim Wasserpreis. Die Forscher schreiben im Fachmagazin Tobacco Control, dass die Reduzierung der Gewinne theoretisch höhere Steuereinnahmen ohne eine Veränderung des Ladenpreises ermöglicht. Die Tobacco Manufacturers's Association findet diesen Vorschlag komplett unverständlich.

Laut Branston macht die Tabakindustrie sehr große Gewinne. Manchen Unternehmen bleiben nach Abzug der Steuern 67 Pence Profit pro Pfund. Einige Industriezweige in Großbritannien unterliegen aufgrund des mangelnden Mitbewerbs bereits Regulierungen. Die Ofwat regelt zum Beispiel den Wasserpreis, den Unternehmen festsetzen können. Die Organisation Ofsmoke soll laut Branston die durch den Verkauf von Rauchwaren erzielten Profite ähnlich regulieren. Auch wenn man die Kosten für die Errichtung einer entsprechenden Behörde und die geringeren Steuereinnahmen der Hersteller berücksichtigt, ist laut Forscherteam mit umfangreichen zusätzlichen Einnahmen zu rechnen. Mit der zusätzlichen halben Mrd. Pfund an Steuern könnten zahlreiche Maßnahmen gegen den Zigarettenschmuggel oder Angebote zur Raucherentwöhnung leicht finanziert werden.

Die Tobacco Manufacturers's Association argumentiert, dass ohnehin schon hohe Steuern gezahlt würden. 2011-2012 seien mehr als 12 Mrd. Pfund an den Fiskus abgeführt worden. Die Steuern bei sehr beliebten Zigarettenmarken lägen bereits bei fast $90 \%$. Die Studie ignoriere diesen Umstand und konzentriere sich stattdessen auf den Gewinn einer Industrie, die in Großbritannien mehr als 70000 Arbeitsplätze schaffe.

Nach einer Mitteilung der pressetext Nachrichtenagentur $\mathrm{GmbH}$ 